\title{
Proton chemical shift anisotropy measurements of hydrogen-bonded functional groups by fast magic-angle spinning solid-state NMR spectroscopy $\dagger$
}

\author{
Luminita Duma, Daniel Abergel, Piotr Tekely* and Geoffrey Bodenhausen
}

Received (in Cambridge, UK) 22nd January 2008, Accepted 19th February 2008

First published as an Advance Article on the web 18th March 2008

DOI: $10.1039 / \mathbf{b 8 0 1 1 5 4 k}$

The suitability of fast MAS solid-state NMR spectroscopy for probing ${ }^{1} \mathbf{H}$ chemical shift anisotropy of hydrogen-bonded species has been demonstrated.

Hydrogen bonds play a central role in determining molecular conformation and aggregation in areas ranging from inorganic to biological chemistry. ${ }^{1,2}$ The description and understanding of the nature of intermolecular contacts in hydrogen-bonded systems remains a challenging problem. Nuclear Magnetic Resonance (NMR) spectroscopy is one of the most suitable tools for studying hydrogen bonding phenomena. Proton NMR spectroscopy has long been used to investigate the nature of hydrogen-bonded systems. ${ }^{3}$ In solids, a range of isotropic chemical shifts of $c a$. 20 ppm is observed for oxygenbound hydrogens. It has been demonstrated theoretically ${ }^{4}$ and experimentally ${ }^{5}$ that the isotropic chemical shifts of hydroxyl or amide protons depend on the $\mathrm{O} \cdots \mathrm{O}$ or $\mathrm{N} \cdots \mathrm{O}$ distances. Modern magic-angle spinning (MAS) equipment allows spinning frequencies that are sufficient to resolve hydrogen-bonded proton sites in aminoacids, peptides and proteins. ${ }^{6}$ However, high-resolution solid state proton spectra on themselves do not give access to the chemical shift anisotropy (CSA) tensors, which provide a better characterization of local electronic environments then their traces. Indeed, changes of the principal elements of the CSA tensors have been shown to be much more sensitive probes of hydrogen bonding than the isotropic chemical shifts. Some aspects of the relationships between the principal elements of ${ }^{15} \mathrm{~N},{ }^{13} \mathrm{C}$ and ${ }^{31} \mathrm{P}$ chemical shift tensors and the strength of hydrogen bonding in peptides and amino acids were recently discussed in the literature. ${ }^{6 c-g, 7-12}$ While hydrogen bonding seems to have a negligible effect on the orientation of ${ }^{15} \mathrm{~N}$ chemical shift tensors in peptides, ${ }^{12 b}$ changes in orientation of ${ }^{31} \mathrm{P}$ chemical shielding tensors due to hydrogen bonding have been revealed in phosphorylated amino acids. ${ }^{6 e-g}$ As far as we know, there are no experimental determinations of ${ }^{1} \mathrm{H}$ chemical shift tensor components in such systems. Indeed, while CSA measurements of rare spins are relatively easy, such a task is much more challenging for hydrogen spins due to the inherently small anisotropies of

Département de Chimie, associé au CNRS, Ecole Normale Supérieure, 24 rue Lhomond, 75231 Paris, Cedex 05, France. E-mail:

Piotr.Tekely@ens.fr; Fax: +33 14432 3397; Tel: + 33144323344

$\dagger$ Electronic supplementary information (ESI) available: ${ }^{1} \mathrm{H}$ MAS spectrum, rotary resonance matching profile and time-dependencies of the signal in octosilicate. See DOI: $10.1039 / \mathrm{b} 801154 \mathrm{k}$ their shielding tensors and strong proton-proton dipolar interactions.

In this communication we demonstrate for the first time the feasibility of probing proton CSA parameters of short hydrogen bonds by fast MAS solid-state NMR spectroscopy. To the best of our knowledge, proton CSA parameters have not been measured so far at spinning frequencies that exceed the magnitude of the anisotropy.

The two-dimensional approach used in our work takes advantage of well resolved isotropic chemical shifts of protons at high MAS frequencies to separate the anisotropic fingerprints from different functional groups. The CSA features are retrieved during the $t_{1}$ evolution from the dephasing of the magnetization under rotary resonance conditions. The rotary resonance effect first observed by Andrew et al. ${ }^{13}$ was originally exploited for recoupling of dipolar interactions by Oas et al. ${ }^{14}$ and for ${ }^{13} \mathrm{C}$ CSA measurements by Gan et al. ${ }^{15}$ The pulse sequence we used consists of a simple spin-lock sequence on the proton channel with an amplitude of the spin-lock rf field matching twice the spinning frequency $\nu_{1 \mathrm{H}}=2 \nu_{r}$, i.e. the so-called $n=2$ rotary resonance condition. ${ }^{14,15}$ As demonstrated below, for relatively isolated hydroxyl protons, the $n=1$ condition $\left(\nu_{1 \mathrm{H}}=\nu_{r}\right)$ can also be used to retrieve the CSA parameters.

Examples of proton CSA fingerprints are shown in Fig. 1 which presents rotary resonance lineshapes of hydrogenbonded silanol groups in octosilicate, a layered hydrous sodium silicate. This class of materials, available only in microcrystalline form, has a two-dimensional layered structure, the negative charge of the silicate layer being compensated by sodium ions that are coordinated by the oxygen atoms of intercalated water molecules. ${ }^{18}$ Hydrous sodium silicates are of growing industrial interest due to their ion- or proton-exchange properties that allow new applications in

Table $1{ }^{1} \mathrm{H}$ NMR shift tensor parameters (in ppm from TMS) in three types of hydrogen bonds

\begin{tabular}{lllllll}
\hline Hydrogen bond & $\begin{array}{l}\delta_{\text {iso/ }} \\
\mathrm{ppm}\end{array}$ & $\begin{array}{l}\delta_{\perp}{ }^{c} / \\
\mathrm{ppm}\end{array}$ & $\begin{array}{l}\delta_{\|}{ }^{c} / \\
\mathrm{ppm}\end{array}$ & $\begin{array}{l}\delta^{d} / \\
\mathrm{ppm}\end{array}$ & $\begin{array}{l}\Omega^{d} / \\
\mathrm{ppm}\end{array}$ & $\begin{array}{l}\kappa^{d} / \\
\mathrm{ppm}\end{array}$ \\
\hline $\mathrm{Si}-\mathrm{O}-\mathrm{H} \cdots \mathrm{O}-\mathrm{Si}^{a}$ & 16.0 & 30.8 & -13.6 & 29.6 & 44.4 & 1.0 \\
$\mathrm{P}-\mathrm{O} \cdots \mathrm{H}-\mathrm{O}-\mathrm{C}^{b}$ & 16.8 & 28.9 & -7.4 & 24.2 & 36.3 & 1.0 \\
$\mathrm{P}-\mathrm{O} \cdots \mathrm{H}-\mathrm{O}-\mathrm{P}^{b}$ & 12.7 & 24.8 & -11.5 & 24.2 & 36.3 & 1.0
\end{tabular}

${ }^{a}$ In octosilicate. ${ }^{b}$ In $O$-phospho-L-serine. ${ }^{c}$ Estimated errors are \pm 1.5 ppm. ${ }^{d}$ Estimated errors are $\pm 1.5 \mathrm{ppm}$. The anisotropy is defined as $\delta=\left|\delta_{\|}-\delta_{\text {iso }}\right|$, the span is expressed as $\Omega=\delta_{\perp}-\delta_{\|}$and the skew as $\kappa=3\left(\delta_{\perp}-\delta_{\text {iso }}\right) / \Omega$. In all cases the asymmetry parameter $\eta$ is zero. 

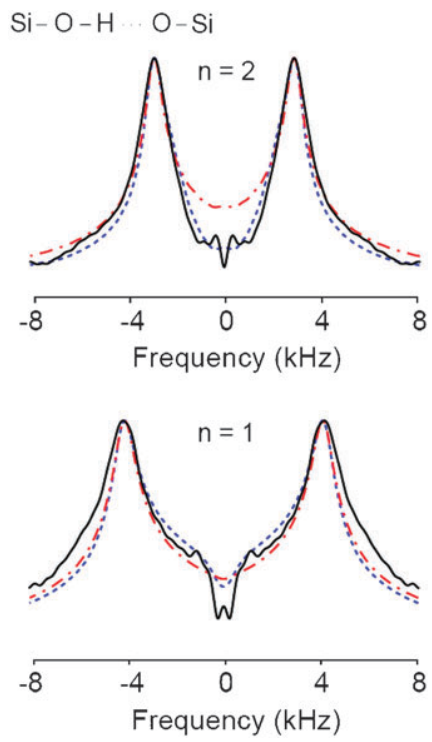

Fig. 1 Proton chemical shift anisotropy fingerprints of hydrogenbonded silanols in a hydrated sodium silicate recorded at a MAS frequency of $10 \mathrm{kHz}$ and at rotary resonance conditions $n=1,2$. The experimental lineshapes (continuous lines) have been simulated using numerical calculations by the SIMPSON program ${ }^{16}$ (-- in blue) and using average Hamiltonian theory ${ }^{17}$ (--- in red). The relevant ${ }^{1} \mathrm{H}$ CSA tensor parameters are reported in Table 1.

catalysis and in the synthesis of composite mesoporous materials. To understand the role of hydrogen bonds in controlling intercalation of polar molecules and the aggregation and ordering of the silicate layers, the correlation of such contacts with spectroscopic fingerprints is highly desired. A ${ }^{1} \mathrm{H}$ MAS NMR spectrum of octosilicate (see ESI $\dagger$ ) acquired at a spinning frequency of $10 \mathrm{kHz}$ proves efficient averaging of the dipolar interactions in this system with moderate ${ }^{1} \mathrm{H}-{ }^{1} \mathrm{H}$ dipolar couplings and permits a clear resolution of two sites at $\delta_{\text {iso }}=3.5$ and $15.98 \mathrm{ppm}$. The latter peak represents hydroxyl protons involved in strong hydrogen bonding, while the former signal corresponds to water molecules. The presence of two well separated proton signals proves that both proton species are not engaged in a rapid exchange process. Previous studies ${ }^{19}$ also provided experimental evidence against rapid proton exchange between hydroxyl groups. For the hydrogen-bonded hydroxyl protons, the simulation of rotary resonance lineshapes in Fig. 1 gives CSA parameters in remarkable agreement with earlier, more elaborated determinations at low spinning speeds. ${ }^{19}$ The somewhat higher wings in the experiments compared with the simulated lineshapes at $n=1$ could be explained by a partial proton-proton dipolar recoupling operating at these conditions. ${ }^{14}$ From the relationships between the principal values, the anisotropy and the $\mathrm{O}-\mathrm{H} \cdots \mathrm{O}$ distance, ${ }^{4}$ one can estimate a distance of $2.48 \pm 0.05$ $\AA$. Such a short distance proves the presence of intralayer, strongly hydrogen-bonded -Si-O-H $\cdots \mathrm{O}-\mathrm{Si}-$ units. $^{19}$

Another example of the effectiveness of the method is for hydrogen-bonded protons from $\mathrm{COOH}$ and $\mathrm{PO}_{2} \mathrm{OH}$ functional groups in $O$-phospho-L-serine. The high speed ${ }^{1} \mathrm{H}$ MAS spectrum of this compound (Fig. 2) reveals well resolved isotropic peaks at $16.8 \mathrm{ppm}$ and $12.7 \mathrm{ppm}$ from the $\mathrm{P}-\mathrm{O}$..

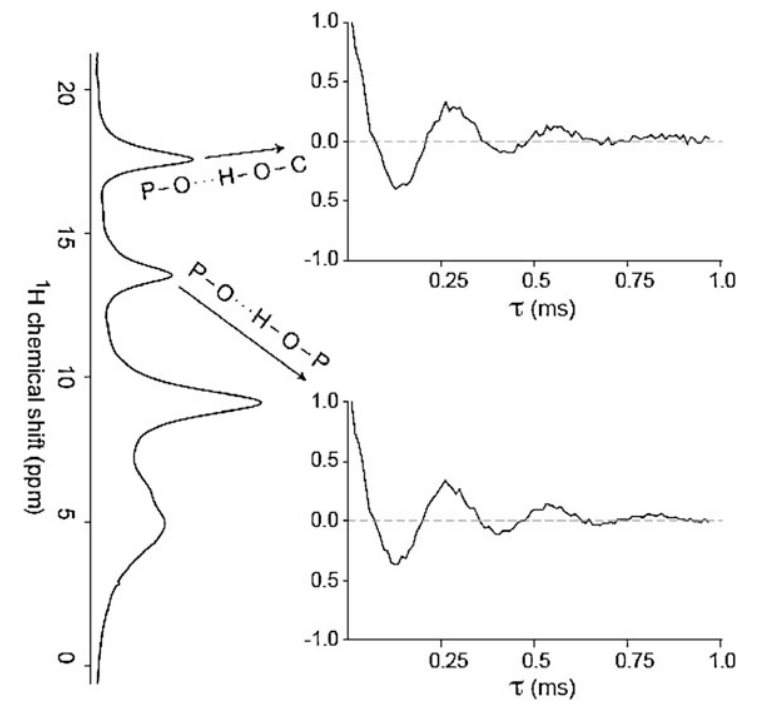

Fig. 2 (Left) $600 \mathrm{MHz}{ }^{1} \mathrm{H}$ MAS NMR spectrum of $O$-phospho-Lserine recorded at a spinning frequency of $25 \mathrm{kHz}$. (Right) Temporal evolution of the magnetization from two different sites at $n=2$ rotary resonance condition. The heteronuclear dipolar recoupling effects were suppressed by the ${ }^{31} \mathrm{P}$ decoupling.

$\mathrm{H}-\mathrm{O}-\mathrm{C}$ and $\mathrm{P}-\mathrm{O} \cdot \cdot \mathrm{H}-\mathrm{O}-\mathrm{P}$ hydrogen-bonded contacts with $\mathrm{O}-\mathrm{H} \cdots \mathrm{O}$ distances of 2.48 and $2.55 \AA$, respectively, as determined by X-rays. ${ }^{20}$ The CSA parameters were obtained by fitting rotary resonance lineshapes (Fig. 3) retrieved from Fourier transformations of the temporal evolution of the magnetization shown in Fig. 2. In accordance with the general picture of the shielding of protons in hydrogen-bonded species, ${ }^{17}$ both types of protons reveal again axially symmetric CSA tensors represented by a prolate $(\kappa=+1)$ ellipsoid.

The numerical simulations (Fig. 3) show that the method should also be useful to measure smaller values of proton chemical shift anisotropies (Fig. 4).
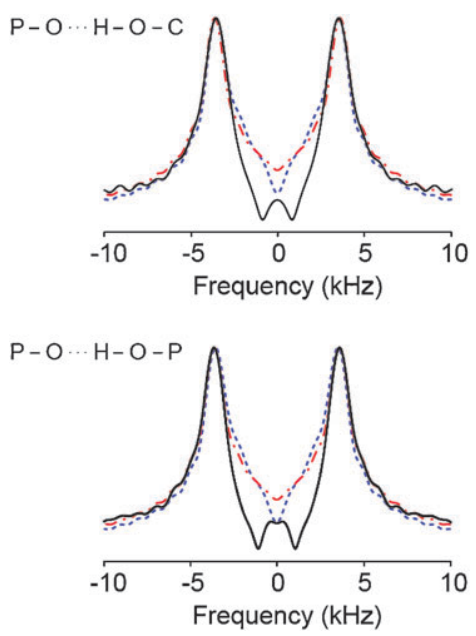

Fig. $3 \quad{ }^{1} \mathrm{H}$ CSA fingerprints of hydrogen-bonded $\mathrm{COOH}$ and $\mathrm{PO}_{2} \mathrm{OH}$ functional groups in O-phospho-L-serine retrieved from Fourier transformations of the temporal evolutions of the signals shown in Fig. 2. The lineshapes have been simulated using SIMPSON (-- in blue) and average Hamiltonian theory (--- in red). The relevant ${ }^{1} \mathrm{H}$ CSA tensor parameters are reported in Table 1. 


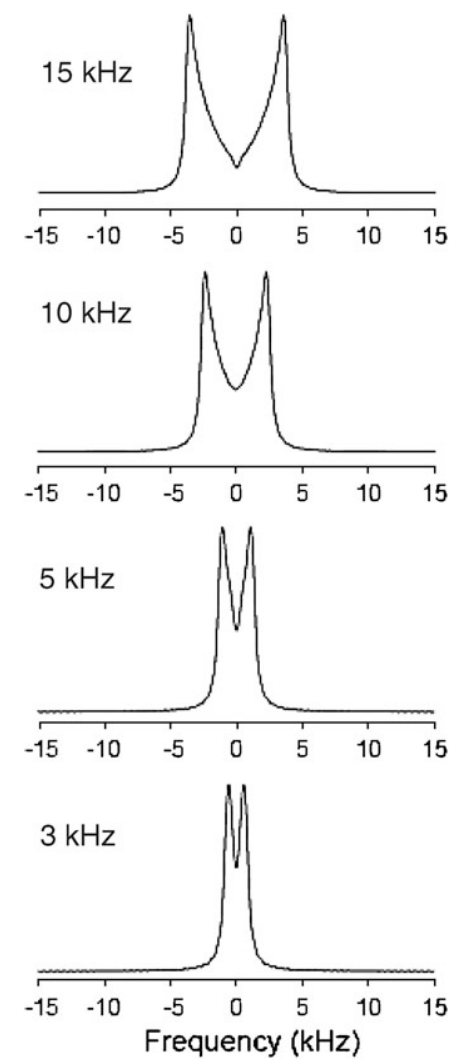

Fig. 4 Simulated ${ }^{1} \mathrm{H}$ CSA rotary resonance $(n=2)$ fingerprints for different anisotropy $\delta$ values of the chemical shift tensor. An axially symmetric CSA tensor and a $25 \mathrm{kHz}$ MAS frequency were used in all cases.

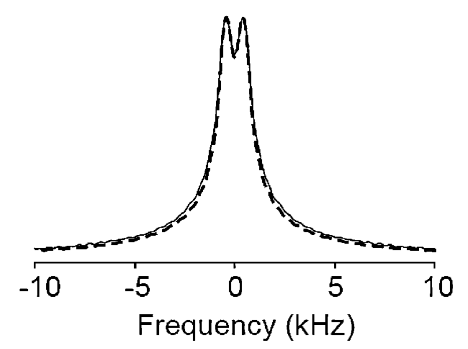

Fig. $5{ }^{1} \mathrm{H}$ CSA fingerprint of water molecules in a hydrated sodium silicate recorded at a MAS frequency of $10 \mathrm{kHz}$ and at the rotary resonance condition $n=2$. The experimental lineshape (continuous line) has been fitted using $\delta=5.0 \mathrm{ppm}$ and $\eta=0$ in SIMPSON calculations (--).

Corroborating evidence is shown in Fig. 5, where a good agreement between experimental and simulated rotary resonance fingerprints for water protons in octosilicate can be observed for an anisotropy $\delta=2.0 \mathrm{kHz}$. Dramatic differences observed in the shape of the rotary resonance features and the fitted anisotropy values of strongly hydrogen-bonded hydroxyl and water protons provide further evidence against rapid proton exchange on the time scale of the experiment.

Summing up, we have shown the feasibility of probing proton CSA parameters of hydrogen-bonded species by fast MAS solid-state NMR spectroscopy. We believe this to be the first measure of proton CSA at high spinning frequencies.
Numerous applications to the studies of intra and intermolecular contacts of hydrogen-bonded organic and inorganic systems can be envisaged.

Financial support from the ANR the SESAME Program of the Région Ile-de-France, the Integrated Infrastructure Initiative (Contract \# RII3-026145, EU-NMR) of the 6th Framework Program of the EU and the CNRS is gratefully acknowledged.

\section{Notes and references}

1 G. A. Jeffrey and W. Saenger, Hydrogen Bonding in Biological Structures, Springer, Berlin/Heidelberg, 1991.

2 T. Steiner, Angew. Chem., Int. Ed., 2002, 41, 48.

3 S. P. Brown and H. W. Spiess, Chem. Rev., 2001, 101, 4125.

4 (a) R. Ditchfield, J. Chem. Phys., 1976, 65, 3123; (b) C. M. Rohlfing, L. C. Allen and R. Ditchfield, J. Chem. Phys., 1983, 79, 4958; (c) S. Hori, K. Yamauchi, S. Kuroki and I. Ando, Int. J. Mol. Sci., 2002, 3, 907; (d) F. Pourpoint, C. Gervais, L. Bonhomme-Coury, T. Azaïs, C. Coelho, F. Mauri, B. Alonso, F. Babonneau and C. Bonhomme, Appl. Magn. Reson., 2007, 32, 435.

5 (a) H. Eckert, J. P. Yesinowski, L. A. Silver and E. M. Stolper, J. Phys. Chem., 1988, 92, 2055; (b) J. P. Yesinowski, H. Eckert and G. R. Rossman, J. Am. Chem. Soc., 1988, 110, 1367; (c) R. K. Harris, P. Jackson, H. Merwin, B. J. Say and G. Hägele, J. Chem. Soc., Faraday Trans. 1, 1988, 84, 3649; (d) G. Wu, C. J. Freure and E. Verdurand, J. Am. Chem. Soc., 1998, 120, 13187.

6 (a) K. Yamauchi, S. Kuroki, K. Fujii and I. Ando, Chem. Phys. Lett., 2000, 324, 435; (b) A. M. Gil, E. Alberti, C. Parreira, B. J. Goodfellow and B. Rakvin, J. Mol. Struct., 2002, 602-603, 357; (c) B. Henry, P. Tekely and J. J. Delpuech, J. Am. Chem. Soc., 2002, 124, 2025; (d) M. J. Potrzebowski, X. Assfeld, K. Ganicz, S. Olejniczak, A. Cartier, C. Gardiennet and P. Tekely, J. Am. Chem. Soc., 2003, 125, 4223; (e) C. Gardiennet, B. Henry, P. Kuad, B. Spiess and P. Tekely, Chem. Commun., 2005, 2, 180; (f) C. Gardiennet-Doucet, X. Assfeld, B. Henry and P. Tekely, J. Phys. Chem. A, 2006, 110, 9137; (g) C. Gardiennet-Doucet, B. Henry and P. Tekely, Prog. Nucl. Magn. Reson. Spectrosc., 2006, 49, 129.

7 S. Ando, I. Ando, A. Shoji and T. Ozaki, J. Am. Chem. Soc., 1988, 110, 3380 .

8 Z. Gu, R. Zambrano and A. McDermott, J. Am. Chem. Soc., 1994, 116, 6368

9 Y. Wei, A. C. de Dios and A. E. McDermott, J. Am. Chem. Soc., 1999, 121, 10389.

10 D. Sitkoff and D. A. Case, Prog. Nucl. Magn. Reson. Spectrosc., 1998, 32, 165

11 (a) M. J. Potrzebowski, C. Schneider and P. Tekely, Chem. Phys. Lett., 1999, 313, 569; (b) R. Colsenet, C. Gardiennet, B. Henry and P. Tekely, Angew. Chem. Int. Ed., 2002, 41, 4743.

12 (a) Y. Wei, D.-K. Lee and A. Ramamoorthy, J. Am. Chem. Soc., 2001, 123, 6118; (b) J. R. Brender, D. M. Taylor and A. Ramamoorthy, J. Am. Chem. Soc., 2001, 123, 914; (c) D.-K. Lee, Y. Wei and A. Ramamoorthy, J. Phys. Chem. B, 2001, 105, 4752.

13 E. R. Andrew, A. Bradbury, R. G. Eades and V. T. Wynn, Phys. Letters, 1963, 4, 99.

14 T. G. Oas, R. G. Griffin and M. H. Levitt, J. Chem. Phys., 1988, 89, 692.

15 Z. Gan, D. M. Grant and R. R. Ernst, Chem. Phys. Lett., 1996, 254, 349.

16 M. Bak, J. T. Rasmussen and N. C. Nielsen, J. Magn. Reson., 2000, 147, 296.

17 U. Haeberlen, Philos. Trans. R. Soc. London, Ser. A, 1981, 299, 497.

18 H. P. Eugster, Science, 1967, 157, 1177.

19 (a) C. Gardiennet, F. Marica, C. A. Fyfe and P. Tekely, J. Chem. Phys., 2005, 122, 054705; (b) C. Gardiennet and P. Tekely, J. Phys. Chem. B, 2002, 106, 8928; (c) C. Gardiennet, F. Marica, X. Assfeld and P. Tekely, Angew. Chem., Int. Ed., 2004, 43, 3565.

20 W. Maniukiewicz, W. Kwiatkowski and R. H. Blessing, Acta Crystallogr., Sect. C: Cryst. Struct. Commun., 1996, C52, 1736. 